\title{
Cancer Immunotherapy Therapeutic Manipulation of the CD8- HLA Class I Interaction: Potential and Challenges
}

\section{P Savage*}

BSUH, Brighton, UK

*Corresponding author: Dr. P Savage, BSUH, Brighton, UK

ther than delivering direct stimulation. Two approaches to this are now in routine clinical practice using monoclonal antibodies that block either the cytotoxic T-lymphocyte-associated protein 4 (CTLA-4) system or the programmed cell death protein 1- programmed death-ligand 1 (PD1-PDL-1) interaction [3]. Both of these therapeutic approaches deliver considerable benefit to patients over an increasingly wide range of cancers including melanoma, lung cancer, renal cancer, Hodgkin's lymphoma and bladder cancer [4-6]. It appears likely that malignancies with high mutational burdens such as melanoma and lung cancer are most likely to respond effectively to these therapies $[7,8]$.

However, the nature of how $T$ cells recognise tumour cells, via the $T$ cell receptor (TCR) interacting with the HLA class I molecule displaying an antigenic peptide of tumour origin, may limit the potential efficacy of cellular immunotherapy $[9,10]$. Typically, these interactions are of low affinity, therefore the resultant strength and specificity of the immune response against tumour cells may remain modest even with the blockade of co-inhibitory receptor pathways. This may in part explain the high proportion of patients that currently do not respond to these therapies.

A second therapeutic approach is to retarget cytotoxic $T$ cells to attack tumour cells using an alternate recognition system aside from the natural TCR/HLA class I peptide interaction. Technologies with this group include; bi-specific antibody fragments, including Blinitumomab [11], which has shown efficacy in leukemia and lymphoma $[12,13]$, chimeric antigen receptor T cells (CAR-T cells) that express a recombinant receptor on the surcell response to tumours, by reducing the natura inhibitory controls of the cellular immune system ra-

Citation: Savage P (2019) Cancer Immunotherapy Therapeutic Manipulation of the CD8-HLA Class I Interaction: Potential and Challenges. Int J Immunol Immunother 6:035. doi.org/10.23937/23783672/1410035

Accepted: February 21, 2019: Published: February 23, 2019

Copyright: (c) 2019 Savage P. This is an open-access article distributed under the terms of the Creative Commons Attribution License, which permits unrestricted use, distribution, and reproduction in any medium, provided the original author and source are credited. 
face of transfected T cells [14] and immune mobilising monoclonal T-cell receptors against cancer (ImmTacs), which target tumour cells via high affinity engineered T cell receptor fragments [15]. However, these systems are complex, expensive and may also have practical limitations to their activity and widespread clinical utility. An alternate approach is to change the immunological appearance of the tumour cell so that it mimics a virally infected cell, with the aim producing cell killing the high levels of naturally occurring virus specific $T$ cells. This aim can be accomplished by delivering recombinant HLA class I molecules which contain a viral peptide to the surface of tumour cells using a monoclonal antibody delivery system.

We originally described this concept using a simple biotin-streptavidin based system. This indicated that recombinant HLA class I peptide complexes when attached to the surface of a tumour cells serve as an efficient target for T cells specific for the HLA class I/ peptide complex and result in effective tumour cell killing $[16,17]$. The technology has been subsequently developed in both the commercial and academic setting using a number of differing antibody delivery systems including; chemical conjugates, HLA-sfv fusion proteins, HLA-IgG fusions and the antibody dock and lock technology [18-20].

Each of these systems demonstrates that effective target cell killing can be produced in vitro and in vivo using re-directed virus specific T cells as the effectors. A more recent publication from the team at Roche gives a good summary of the potential of the technology [21]. However, whilst each of these delivery systems appear to offer effective in vitro and in vivo target cell killing the physiological restriction of the immune response to a single HLA allele/peptide may limit both the efficacy and applicability of the system.

Here we discuss how engineering changes to the protein structure of the HLA class I molecule can dramatically alter the affinity of the interaction with the CD8 coreceptor expressed at the $T$ cell surface and how the resultant changes in T cell activation and even specificity could potentially be exploited.

\section{CD8-HLA Class I Interaction: Potential as an Immunotherapeutic Target}

\section{Overview of the CD8-HLA alpha 3 interaction}

CD8 is a transmembrane glycoprotein of the immunoglobulin superfamily expressed on the surface of cytotoxic T cells. The cell surface molecule can be present as either an alpha-alpha homodimer or alpha-beta heterodimer. The alpha and beta chains of CD8 are similar, in that they both have a short cytoplasmic region, a single transmembrane domain, a glycosylated stalk and an immunoglobulin like extra-cellular domain [22].

The alpha-beta CD8 heterodimer is expressed only on conventional HLA class I restricted alpha beta TCR+ cytotoxic T cells. In contrast, the CD8 alpha-alpha homodimer, whilst present in low levels on CD8 T cells, is also expressed on additional cell subsets such as gamma delta T cells and NK cells [23,24].

The main interaction between CD8 and the HLA class I molecule occurs via a short length of monomorphic amino acids on the alpha 3 domain of the HLA molecule

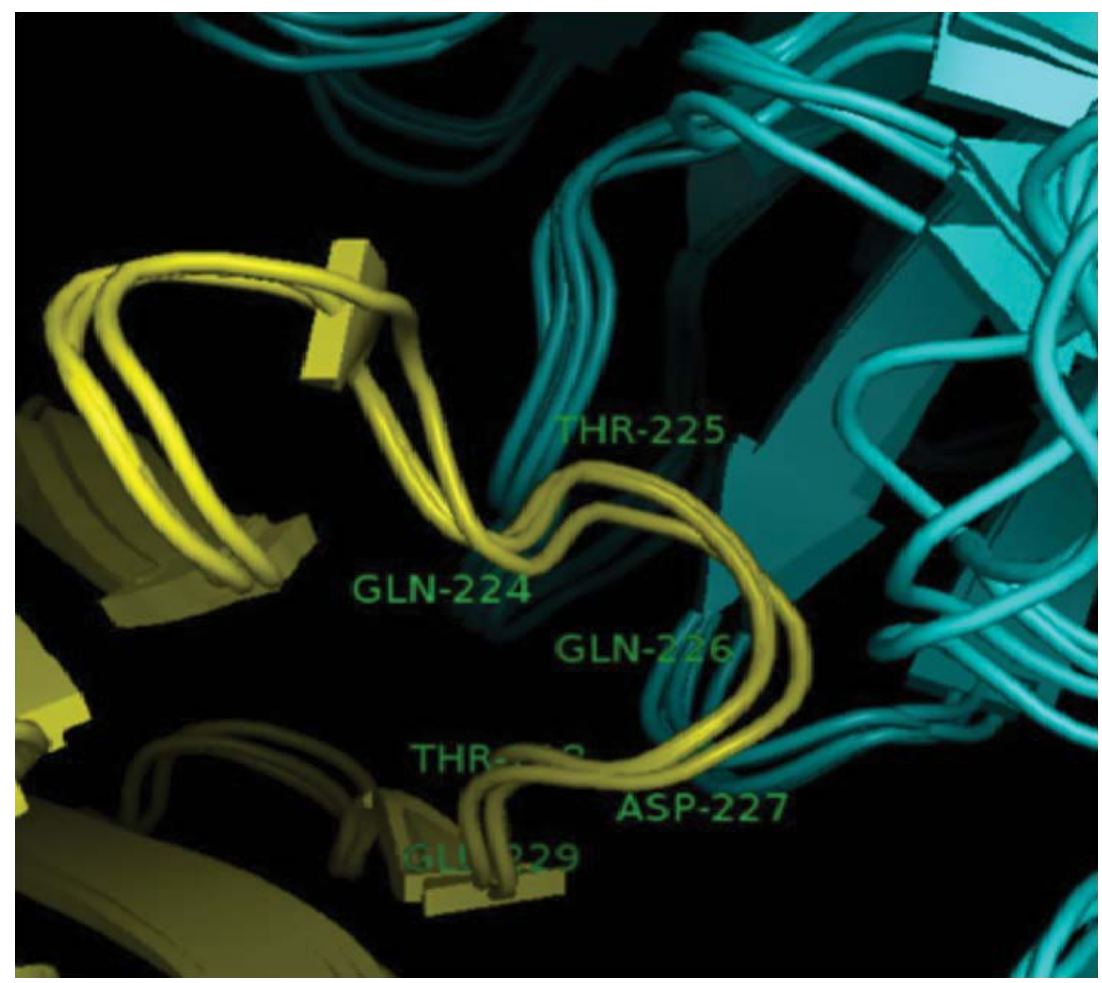

Figure 1: The interaction between the wild type HLA class I alpha 3 loop, residues 224-229 (yellow) and CD8 (blue). Only the path of the protein backbone is shown in cartoon representation, for clarity. 
[25]. At this point two complementary determining region (CDR) like loops of the CD8 molecule interact with an area encompassing residues 223-227 of the HLA class I alpha 3 domain as shown in Figure 1.

The native CD8-HLA class I interaction is characterized by a relatively low affinity $(K D=145 \mu \mathrm{M})$ and rapid kinetics [26-28]. This contrasts with the generally higher affinity of the interaction ( $K D=1-10 \mu \mathrm{M})$ seen between the TCR and HLA class I/peptide complex [29].

Despite the low affinity, the binding of the HLA class I molecule to CD8 at the cell surface enhances the association rate of HLA class I complexes with TCRs and increases the interaction half-life [30]. In addition to stabilising the TCR/peptide-HLA interaction, the binding of CD8 leads to recruitment of p56lck and triggers signalling pathways downstream of the TCR/HLA triggering [31].

\section{The impact of affinity changes of the CD8-HLA class $\mathrm{I}$ interaction on $\mathrm{T}$ cell activation and target killing}

Previous in vitro studies using point mutation changes to the HLA class I alpha 3 domain that alter the binding affinity of the CD8-HLA class I interaction, have demonstrated very significant changes to $T$ cell activity. Abrogation of this interaction can be produced via an amino acid substitution (D227K/T228A) in the alpha 3 domain of the HLA class I molecule. This leads to a reduction in the binding affinity to $K D>10,000 \mu \mathrm{M}$ and a dramatic reduction in production of cytokines and lytic ability of T cells on interaction with their target cells as shown in Figure 2.

In contrast changes (Q115E) that moderately increase the native affinity of the CD8-HLA class I interaction to $K D \sim 85 \mu \mathrm{M}$ result in enhancement of $\mathrm{T}$ cell activity compared to the wild type HLA-A2 as shown in Figure 2. However, whilst the strength of the $T$ cell immune response to cells bearing the appropriate HLA class I/ peptide complex is significantly enhanced by this modest change the $\mathrm{T}$ cell -target cell specificity is unchanged [32].

When the affinity of the CD8-HLA class I interaction is increased further to $K D \sim 10 \mu \mathrm{M}$, by engineering a chimeric $\mathrm{HLA}-\mathrm{A} 2 / \mathrm{Kb}$ molecule, that bears the murine $\mathrm{MHC}$ alpha 3 domain, there is a dramatic change in the specificity of the $T$ cell interaction. In this situation, there is loss of T cell HLA/peptide specificity and T cells of any specificity can be activated via this interaction with the enhanced HLA class I molecule irrespective of the identity of the presented peptide [33].

Whilst to date, the published data has focused on the activation and expansion of $\mathrm{T}$ cells, our recent data indicates that target cells bearing $\mathrm{HLA}-\mathrm{A} 2 / \mathrm{Kb}$ complexes can be killed by CD8 T cells irrespective of their cognate HLA or peptide specificity. The data in Figure $3 a$ indicates that $T$ cell clones with native specificity for either HLA-A2 or HLA-B35 can effective kill $\mathrm{A} 2 / \mathrm{Kb}$ targets, whilst in Figure $3 \mathrm{~b}$ purified peripheral blood CD8 cells from A2+ve and A2-ve donors both also produce effective killing of the target cells bearing $\mathrm{HLA}-\mathrm{A} 2 / \mathrm{Kb}$.

These initial results suggest that manipulating the CD8-HLA class I interaction can have very significant effects on T cell activity and potentially on T cell specificity, which could both be of significant clinical utility.

\section{Therapeutic Exploitation of this Immunologi- cal Mechanism}

Modifications of the CD8-HLA class I interaction

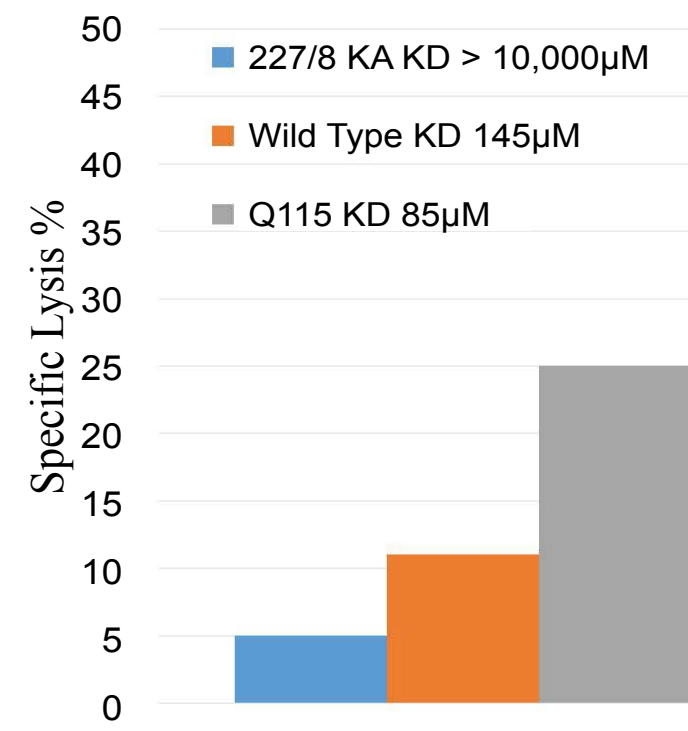

T cell Clone 868

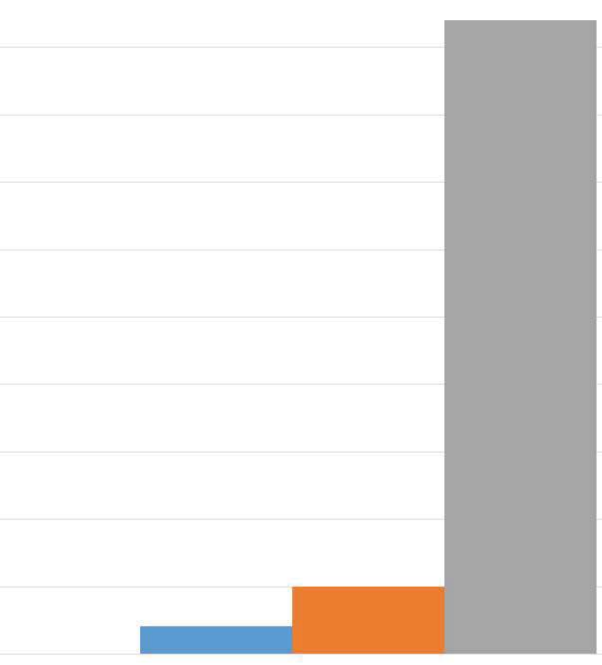

T cell Clone $1 \mathrm{C} 2$

Figure 2: The impact of changes in CD8-HLA class I binding affinities on T cell allele/peptide specific lytic function. The ability of two HLA-A2 specific T cell lines (868 and 1C2) to produce cell lysis of peptide pulsed C1R-A2 bearing HLA-A2 molecules of differing affinities. 227/8KA (> 10,000 $\mu \mathrm{M})$, Wildtype $(145 \mu \mathrm{M})$ and Q115 $(85 \mu \mathrm{M})$. Data from reference $(32)(\mathrm{E}: \mathrm{T} 2: 1,2 \mathrm{hour}$ incubation). 
A) 30

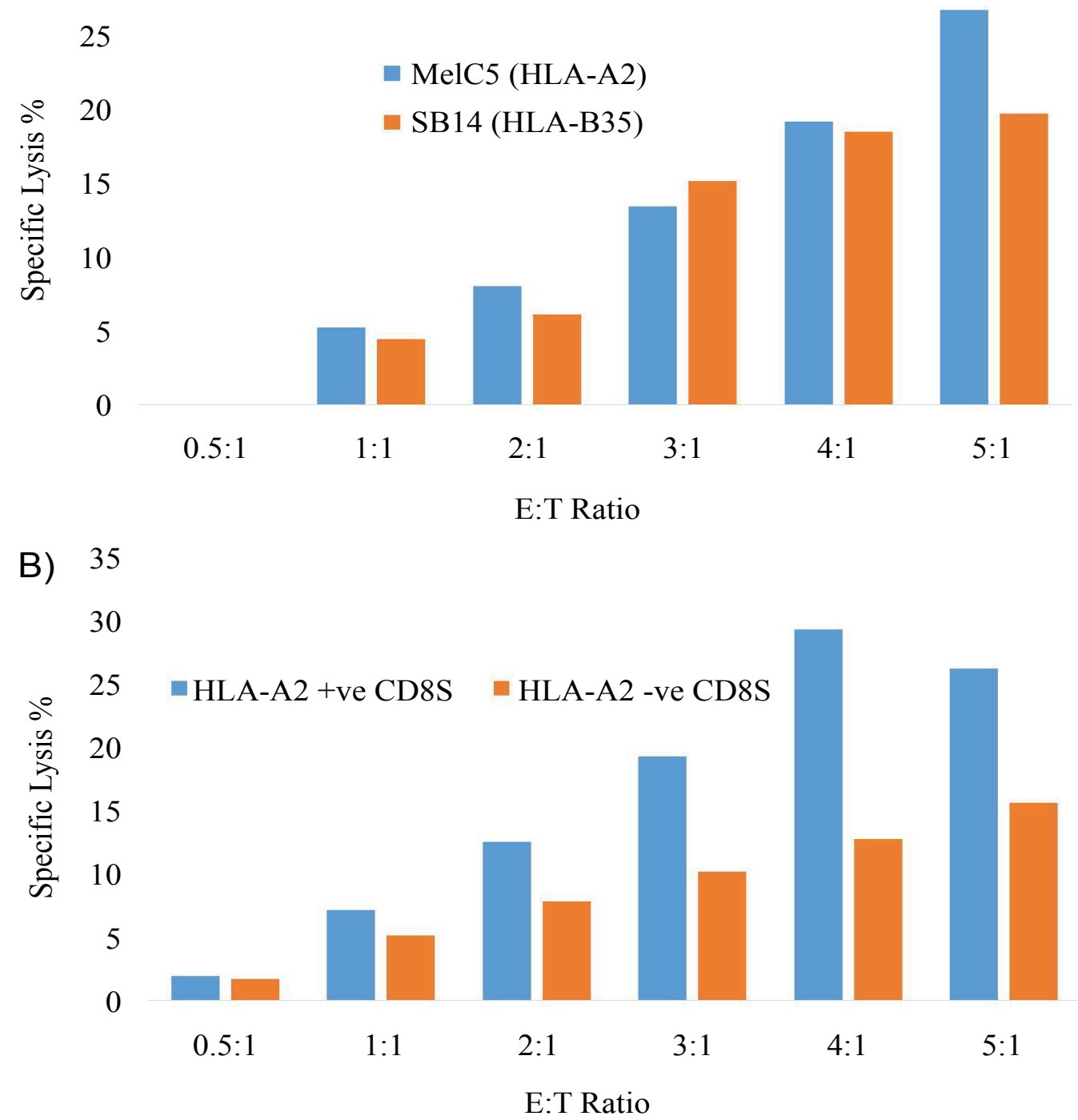

Figure 3: a,b) HLA class I unrestricted T cell clone mediated lysis of C1R B cells expressing HLA-A2/Kb.

For these FATAL assays $3 \times 10^{4}$ eF670+ HLA-A2/Kb+ C1Rs and control eF670- HLA-A2wt+ C1Rs cells were combined with CD8+ T-cells at varying (E:T) ratios: Assays containing no CD8+ effector T-cells were used as a baseline to measure background cell death. Following a 12-hour incubation period $\left(37^{\circ} \mathrm{C}, 0.5 \% \mathrm{CO}_{2}\right)$, the cells were harvested, stained with antiCD8-BV785 and the viability dye Aqua, prior to data acquisition on a Fortessa flow cytometer (BD Biosciences).

Specific lysis of HLA-A2Kb-expressing targets by HLA-A2 and non-HLA-A2 restricted CD8+ T-cell clones MelC5 (specific for HLA-A2/melan-A) and SB14 (specific for HLA-B35/EBNA-1) are shown in Figure 3a.

In Figure $3 b$ the same system is used to demonstrate the specific lysis from expanded CD8+ve $T$ cells sourced from the PBMCs of HLA-A2+ or HLA-A2-ve donors.

could be potentially exploited in 3 ways as discussed below;

\section{Delivery of HLA-A2/Kb cDNA by gene delivery te- chnology}

Until recently gene delivery mediated cancer therapy had struggled in clinical development. More recently clinical developments in cancer virotherapy have altered this with a licenced gene mediated therapy based on intratumoral injection [34]. With evolving technology more ambitious gene mediated therapies that are activated only in designated targeted cancer cells appear a realistic future expectation [35].

The observation that target cells bearing the
$\mathrm{HLA}-\mathrm{A} 2 / \mathrm{Kb}$ complexes can be killed by activated CD8 $T$ cells of any HLA/peptide specificity suggests that delivery of these complexes by gene transfer could offer a new approach to therapy. The expectation is that expression of these complexes combined with activation of the immune system by either cytokines or PD1 inhibitors could lead to T cell mediated lysis of targeted tumour cells by activated normal T cells in all patients irrespective of their HLA type or pre-existing anti-tumour immune response.

Additionally, as the HLA-A2/Kb complexes produce activation and expansion of all T cells irrespective of native specificity, the presence of cells expressing $A 2 / K b$ complexes within the tumour environment may enhan- 
Table 1: Summary of the impact of binding affinity changes in the CD8-Hla Class I interaction, the potential immunotherapy agonist and antagonist drug actions and their impact on immunological function.

\begin{tabular}{|l|l|l|l|}
\hline Interaction & $\begin{array}{l}\text { Binding Affinity } \\
\left(\mathbf{K}_{\mathbf{D}}\right)\end{array}$ & $\begin{array}{l}\text { CD8-HLA Class I } \\
\text { Drug Action }\end{array}$ & Immunological Outcome \\
\hline CD8- HLA Class I Wild Type & $145 \mu \mathrm{M}$ & Nil & Normal T Cell Activity \\
\hline CD8-HLA Class I (Q115E) & $85 \mu \mathrm{M}$ & Weak Agonist & $\begin{array}{l}\text { Enhanced Activity Cognate Specificity } \\
\text { Enhanced T Cell Specific Killing }\end{array}$ \\
\hline CD8-HLA-A2/K & $10 \mu \mathrm{M}$ & Strong Agonist & $\begin{array}{l}\text { Loss of Cognate HLA/Peptide Specificity } \\
\text { Targets Killed by all T Cells }\end{array}$ \\
\hline CD8 -HLA Class I (D227K/T228A) & $>10,000 \mu \mathrm{M}$ & Antagonist & Loss of T Cell Activity \\
\hline
\end{tabular}

ce the impact of PD1 based therapies by expanding and enhancing local tumour specific $T$ cell responses against the largely unknown tumour epitopes [32].

With the ability to effectively control T cell activation, the challenge now is how to selectively deliver and express the gene for HLA-A2/Kb or similar HLA class I derivatives with high affinity CD8 interactions.

\section{Delivery via an antibody-HLA class I system}

This technology closely parallels that of bispecific antibodies, has already had considerable development with a variety of systems using the standard HLA class I molecule. Whilst our recent work has used transfected cells with cell surface protein expression, our previous work has indicated that antibody delivered HLA molecules have similar immunological recognition characteristics [36].

Recent publications from the team at Roche indicate that the technology of antibody-HLA targeting may be moving towards clinical applicability. However, the limited immunological specificity of the current targeting systems may well limit the efficacy and clinical utility. In the current formulations of the technology the targeting system includes only a single HLA/peptide complex. This will be recognised by virus specific $T$ cells that are efficient cytotoxic CD8 T cells but only comprise a very small proportion of the total CD8 T cell population. Additionally, there is the limitation that a range of differing constructs would be needed for patients of differing HLA class I.

The use of the HLA-A2/Kb molecule or derivatives could help overcome both of these issues as they would be recognised by the full range of $T$ cells of all specificities and so harness cytotoxic CD8 T cell activity in each patient irrespective of patient HLA tissue type.

The use of an antibody delivery system to deliver the HLA-A2/Kb molecule may carry a risk that the HLA-A2/Kb molecule may be potentially immunogenic and could, unlike the standard HLA class I molecule, potentially lead to unwanted $T$ cell activation distant from the tumour as circulating $T$ cells interact with this new HLA construct. Forthcoming experiments examining the potential impact of soluble monomeric HLA-A2/Kb on T cell activation should provide insight into this risk.

\section{Targeting the CD8-HLA class I immune Interface with agonist/antagonist drugs}

The impact of the CD8-HLA class I interaction on determining both the degree of activation and specificity of the $T$ cell target interaction is based on a manipulating a natural low affinity interaction.

The Table 1 below summarises the variation in the interactions, the affinity of the binding and the potential immunological outcomes.

To date the affinity of this interaction has been manipulated predominantly by using protein engineering approaches. A key question is, if using more modern technology, can the CD8-HLA class I interaction be either enhanced or weakened using drugs that target this protein-protein interaction? The development of drugs that inhibit or act as agonists in protein-protein interactions is now a rapidly evolving area of therapeutic research and development $[37,38]$.

The 3D crystal structure of the CD8-HLA class I interaction is well characterised and some of the key amino acid interactions have been previously demonstrated. We have examined the crystal structure of the CD8-HLA class I interface to assess if it could be possible to inhibit or enhance this binding via novel drugs impacting on this protein-protein interface. A computer representation of the interface between these two molecules is shown below in Figure 4, including the area that may be suitable to be 'drugged'.

\section{Antagonists}

Previous work with peptides, recombinant soluble CD8 and beta 2 microglobulin derivatives have shown significant immunological inhibition but have not been developed clinically [39-41]. More recent data using an antibody that binds to CD8 has demonstrated profound reductions in T cell activity [42]. Whilst the biological impact of this inhibition is important, the duration of activity with an antibody system may be too long for clinical application. Other technology that could achieve similar but more controllable inhibition may be of value in autoimmunity and the management of cancer immunotherapy toxicity.

\section{Weak agonist}

The protein engineering data indicates that incre- 


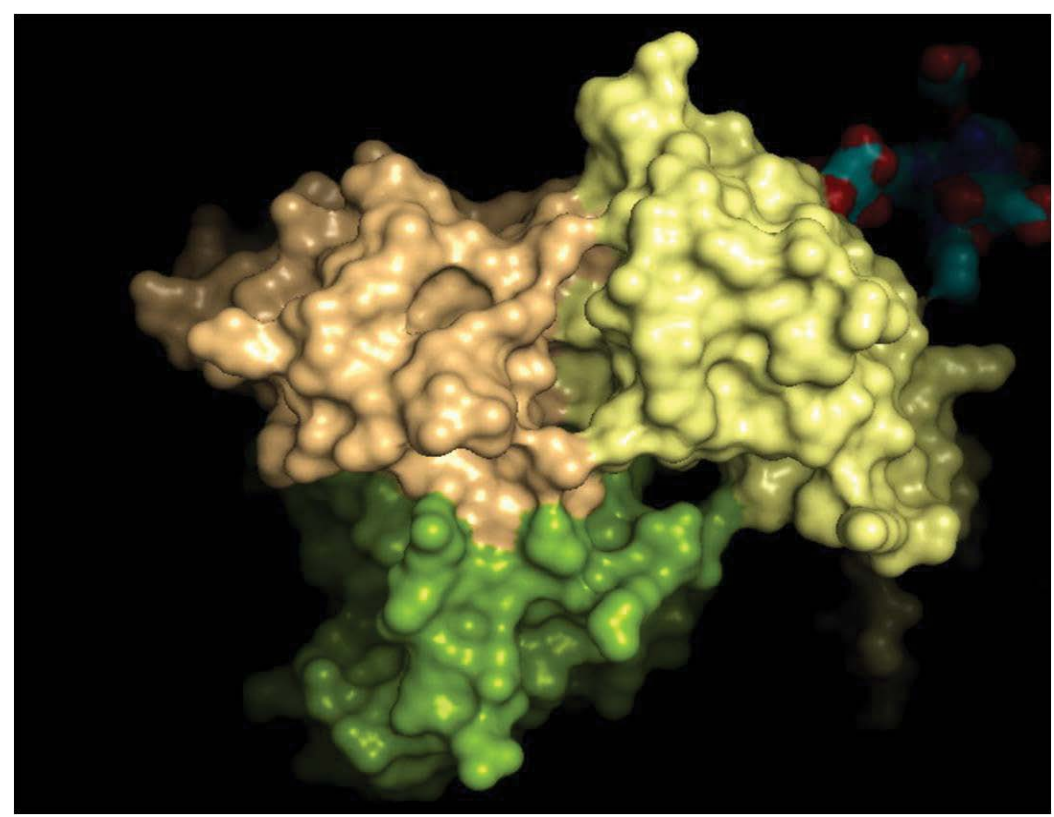

Figure 4: The HLA-CD8 complex (1AKJ crystal structure; HLA, yellow; CD8 domains in beige and green). The structures of the complexes show that there are several regions adjacent to contacts between chains that present cavities into which a small molecule could bind to exert agonist or antagonist properties.

asing the affinity of the CD8-HLA class I interaction from a KD of $145 \mu \mathrm{M}$ to $85 \mu \mathrm{M}$ results in enhanced T cell activation and target cell killing whilst maintaining HLA/peptide specificity [32]. The key question is if a drug that moderately strengthens the CD8-HLA class I protein-protein interaction will have a similar impact on enhancing $T$ cell activation and killing abilities. If this is the case, then a drug with these characteristics that moderately increases the affinity of the CD8-HLA class I interaction may be of use an adjuvant to vaccination and also therapeutically as an approach to enhancing $T$ cell responses to tumour cells in immune checkpoint inhibitor therapy.

\section{Strong agonist}

A further increase in the affinity of the CD8-HLA class I interaction to a KD of $10 \mu \mathrm{M}$ using the HLA-A2/Kb- Supertarget leads to the loss of HLA/peptide specificity and this allows activated CD8 T cells of all specificities to kill targeted cells. The impact of this is demonstrated in Figures $3 a$ and Figure $3 \mathrm{~b}$ in which $\mathrm{T}$ cells are killing target cells bearing the HLA-A2/Kb molecule regardless of their normal HLA or peptide specificity.

In this situation, if a drug is able to strengthen the interaction it could lead to HLA and peptide independent killing by activated $T$ cells in the environment where the drug is present. In this situation the ability of activated T cells to kill tumour cells would not be by the detection of specific tumour associated peptide, but by selective geographical targeting and delivery of the strong agonist drug to the area of the tumour. A drug with this effect would have the potential to lead to potential $T$ cell/T cell fratricidal killing as well as T cell/target cell killing. A therapy based on a strong agonist would clearly need the availability of a higher affinity inhibitory antagonist to be available to limit unwanted activity and toxicity.

This approach is clearly a novel concept and will require many key steps in development however nanotechnology and antibody-based systems to selectively deliver other drugs/peptides selectively to tumours are already under development [43-45].

\section{Summary}

Tumour immunotherapy is now centre stage in cancer research and modern oncology practice, however despite the many advances the current technologies can be complex and often produce relatively modest results.

For a number of years, we and a number of other groups, have explored the use of antibody targeted HLA class I molecules to redirect T cells to kill tumour cells. However, the clinical utility of this technology may be limited due to the narrowness of the immune response exploited in the system. The recent data shown here indicates that the HLA-A2/Kb molecule can serve as a universal target to all activated CD8 T cells from any patient. This suggests that efficacy and utility could be dramatically high with this revised system and a re-evaluation of the antibody-HLA system and parallel gene delivery systems is indicated.

Alongside this data, the modern developments in drug design suggests that it may be possible to manipulate the CD8-HLA class I interaction with novel drugs rather than protein engineering. It is possible that three simple drugs could be developed that would change this protein-protein interaction. These drugs would allow the choice of downregulating $T$ cell activity, moderately enhancing it, or non-specifically activating $T$ cells which would allow $T$ cells to kill targeted tumour cells irre- 
spective of their native immunological identity.

At present for this application we have little data, however the basic science is supportive, the technology achievable and the potential clinical rewards substantial.

\section{Acknowledgements}

I would like to thank Professor Linda Wooldridge and Dr Anya Lissina for providing the data displayed in Figure 3a \& Figure 3b. Thanks to Professor Scott Burrows for the use of the T cell clone SB10.

\section{References}

1. Klapper JA, Downey SG, Smith FO, Yang JC, Hughes MS, et al. (2008) High-dose interleukin-2 for the treatment of metastatic renal cell carcinoma: A retrospective analysis of response and survival in patients treated in the surgery branch at the national cancer institute between 1986 and 2006. Cancer 113: 293-301.

2. van der Burg SH, Arens R, Ossendorp F, van Hall T, Melief CJ (2016) Vaccines for established cancer: Overcoming the challenges posed by immune evasion. Nat Rev Cancer 16: $219-233$.

3. Krummel MF, Allison JP (1995) CD28 and CTLA-4 have opposing effects on the response of $T$ cells to stimulation. $J$ Exp Med 182: 459-465.

4. Hodi FS, O'Day SJ, McDermott DF, Weber RW, Sosman JA, et al. (2010) Improved survival with ipilimumab in patients with metastatic melanoma. N Engl J Med 363: 711723.

5. Topalian SL, Sznol M, McDermott DF, Kluger HM, Carvajal $\mathrm{RD}$, et al. (2014) Survival, durable tumor remission, and long-term safety in patients with advanced melanoma receiving nivolumab. J Clin Oncol 32: 1020-1030.

6. Balar AV, Castellano D, O'Donnell PH, Grivas P, Vuky J, et al. (2017) First-line pembrolizumab in cisplatin-ineligible patients with locally advanced and unresectable or metastatic urothelial cancer (KEYNOTE-052): A multicentre, single-arm, phase 2 study. Lancet Oncol 18: 1483-1492.

7. Hugo W, Zaretsky JM, Sun L, Song C, Moreno BH, et al. (2017) Genomic and transcriptomic features of response to anti-pd-1 therapy in metastatic melanoma. Cell 168: 542.

8. Rizvi NA, Hellmann MD, Snyder A, Kvistborg P, Makarov $V$, et al. (2015) Cancer immunology. Mutational landscape determines sensitivity to PD-1 blockade in non-small cell lung cancer. Science 348: 124-128.

9. Engels B, Engelhard VH, Sidney J, Sette A, Binder DC, et al. (2013) Relapse or eradication of cancer is predicted by peptide-major histocompatibility complex affinity. Cancer Cell 23: 516-526.

10. Buhrman JD, Slansky JE (2013) Improving T cell responses to modified peptides in tumor vaccines. Immunol Res 55: 34-47.

11. Loffler A, Kufer $P$, Lutterbuse R, Zettl F, Daniel PT, et al. (2000) A recombinant bispecific single-chain antibody, CD19 $x$ CD3, induces rapid and high lymphoma-directed cytotoxicity by unstimulated $\mathrm{T}$ lymphocytes. Blood 95 : 2098-2103.

12. Topp MS, Kufer P, Gokbuget N, Goebeler M, Klinger M, et al. (2011) Targeted therapy with the T-cell-engaging antibody blinatumomab of chemotherapy-refractory minimal residual disease in B-lineage acute lymphoblastic leukemia patients results in high response rate and prolonged leukemia-free survival. J Clin Oncol 29: 2493-2498.

13. Viardot A, Goebeler ME, Hess G, Neumann S, Pfreundschuh M, et al. (2016) Phase 2 study of the bispecific T-cell engager (BiTE) antibody blinatumomab in relapsed/refractory diffuse large B-cell lymphoma. Blood 127: 1410-1416.

14. Jackson HJ, Rafiq S, Brentjens RJ (2016) Driving CAR T-cells forward. Nat Rev Clin Oncol 13: 370-383.

15. Liddy N, Bossi G, Adams KJ, Lissina A, Mahon TM, et al. (2012) Monoclonal TCR-redirected tumor cell killing. Nat Med 18: 980-987.

16. Ogg G, Dunbar P, Cerundolo V, McMichael A, Lemoine $\mathrm{N}$, et al. (2000) Sensitization of tumour cells to lysis by virus-specific CTL using antibody-targeted MHC class I/peptide complexes. Br J Cancer 82: 1058-1062.

17. Savage $P$, Cowburn $P$, Clayton A, Man S, Lawson T, et al. (2002) Anti-viral cytotoxic T cells inhibit the growth of cancer cells with antibody targeted HLA class I/peptide complexes in SCID mice. Int J Cancer 98: 561-566.

18. Lev A, Novak H, Segal D, Reiter Y (2002) Recruitment of CTL activity by tumor-specific antibody-mediated targeting of single-chain class I MHC-peptide complexes. J Immunol1 69: 2988-2996.

19. Donda A, Cesson V, Mach JP, Corradin G, Primus FJ, et al. (2003) In vivo targeting of an anti-tumor antibody coupled to antigenic MHC class I complexes induces specific growth inhibition and regression of established syngeneic tumor grafts. Cancer Immun.

20. King BC, Hamblin AD, Savage PM, Douglas LR, Hansen $\mathrm{TH}$, et al. (2013) Antibody-peptide-MHC fusion conjugates target non-cognate $\mathrm{T}$ cells to kill tumour cells. Cancer Immunol Immunother 62: 1093-1105.

21. Schmittnaegel M, Levitsky V, Hoffmann E, Georges G, Mundigl O, et al. (2015) Committing cytomegalovirus-specific cd8 t cells to eliminate tumor cells by bifunctional major histocompatibility class i antibody fusion molecules. Cancer Immunol Res 3: 764-776.

22. Norment A, Salter R, Parham $P$, Engelhard V, Littman D (1998) Cell-cell adhesion mediated by CD8 and MHC class I molecules. Nature 336: 79-81.

23. Terry L, DiSanto J, Small T, Flomenberg N (1990) Differential expression and regulation of the human CD8 and CD8 chains. Tissue Antigens 35: 82-91.

24. Gangadharan D, Cheroutre $\mathrm{H}$ (2004) The CD8 isoform CD8 is not a functional homologue of the TCR co-receptor CD8. Curr Opin Immunol 16: 264-270.

25. Gao G, Tormo J, Gerth U, Wyer J, McMichael A, et al. (1997) Crystal structure of the complex between human CD8alpha(alpha) and HLA-A2. Nature 387: 630-634.

26. Wyer J, Willcox B, Gao G, Gerth U, Davis S, et al. (1999) T cell receptor and coreceptor CD8 bind peptide-MHC independently and with distinct kinetics. Immunity 10: 219-225.

27. Hutchinson S, Wooldridge L, Tafuro S, Laugel B, Glick M, et al. (2003) The CD8 T cell coreceptor exhibits disproportionate biological activity at extremely low binding affinities. J Biol Chem 278: 24285-24293.

28. Bridgeman JS, Sewell AK, Miles JJ, Price DA, Cole DK (2012) Structural and biophysical determinants of $\alpha \beta$ T-cell antigen recognition. Immunology 135: 9-18.

29. Stone JD, Chervin AS, Kranz DM (2009) T-cell receptor 
binding affinities and kinetics: Impact on T-cell activity and specificity. Immunology 126: 165-176.

30. Wooldridge L, van den Berg HA, Glick M, Gostick E, Laugel B, et al. (2005) Interaction between the CD8 coreceptor and major histocompatibility complex class I stabilizes T cell receptor-antigen complexes at the cell surface. J Biol Chem 280: 27491-27501.

31. Artyomov MN, Lis M, Devadas S, Davis MM, Chakraborty AK (2010) CD4 and CD8 binding to MHC molecules primarily acts to enhance Lck delivery. Proc. Natl. Acad. Sci. USA 107: 16916-16921.

32. Wooldridge L, Lissina A, Vernazza J, Gostick E, Laugel B, et al. (2007) Enhanced immunogenicity of CTL antigens through mutation of the CD8 binding MHC class I invariant region. Eur J Immunol 37: 1323-1333.

33. Wooldridge L, Clement M, Lissina A, Edwards ES, Ladell K, et al. (2010) MHC class I molecules with Superenhanced CD8 binding properties bypass the requirement for cognate TCR recognition and nonspecifically activate CTLs. J Immunol 184: 3357-3366.

34. Andtbacka RH, Kaufman HL, Collichio F, Amatruda T, Senzer N, et al. (2015) Talimogene laherparepvec improves durable response rate in patients with advanced melanoma. J Clin Oncol 33: 2780-2788.

35. Dai W, Xu X, Wang D, Wu J, Wang J (2019) Cancer therapy with a CRISPR-assisted telomerase-activating gene expression system. Oncogene.

36. Mous R, Savage $P$, Eldering $E$, Teeling $P$, van Oers $M H$, et al. (2008) Adequate synapse formation between leukemic $B$ cells and effector $T$ cells following stimulation with artificial TCR ligands. Leuk Lymphoma 49:1592-1602.
37. Arkin MR, Tang Y, Wells JA (2014) Small-molecule inhibitors of protein-protein interactions: Progressing toward the reality. Chem Biol 21: 1102-1114.

38. Petta I, Lievens S, Libert C, Tavernier J, De Bosscher K (2016) Modulation of protein-protein interactions for the development of novel therapeutics. Mol Ther 24: 707-718.

39. Peng Y, Falck-Pedersen E, Elkon KB (2000) Soluble CD8 attenuates cytotoxic $T$ cell responses against replication-defective adenovirus affording transprotection of transgenes in vivo. J Immunol 165: 1470-1478.

40. Choksi S, Kim JC, Whitaker-Menezes D, Murphy GF, Friedman TM, et al. (2004) A CD8 DE loop peptide analog prevents graft-versus-host disease in a multiple minor histocompatibility antigen-mismatched bone marrow transplantation model. Biol Blood Marrow Transplant 10: 669-680.

41. Glick M, Price DA, Vuidepot AL, Andersen TB, Hutchinson SL, et al. (2002) Novel CD8+ T cell antagonists based on beta 2-microglobulin. J Biol Chem 277: 20840-20846.

42. Clement M, Pearson JA, Gras S, van den Berg HA, Lissina $A$, et al. (2016) Targeted suppression of autoreactive CD8+ T-cell activation using blocking anti-CD8 antibodies. Sci Rep 6: 35332.

43. Haley B, Frenkel E (2008) Nanoparticles for drug delivery in cancer treatment. Urol Oncol 26: 57-64.

44. Alley SC, Okeley NM, Senter PD (2010) Antibody-drug conjugates: Targeted drug delivery for cancer. Curr Opin Chem Biol1 4: 529-537.

45. Rodzinski A, Guduru R, Liang P, Hadjikhani A, Stewart T, et al. (2016) Targeted and controlled anticancer drug delivery and release with magnetoelectric nanoparticles. Sci Rep 6: 20867. 